\title{
Constructability and Performance of Continuous Masonry Wall Panels
}

\author{
J.M.N.U.J Manike and H.P Sooriyaarachchi
}

\begin{abstract}
Clay bricks and ccment sand blocks are the most ustual types used for wall panel construction. However, the shortage of raw materials and cost has led to development of many alternatives for conventional brick wall construction. This study presents the development of semi mechanized shutter for the continuous masonry construction, details of the mortar mixes that can be used and load bearing capacity of continuos masonry wall panels. Wall panel construction using this technique was pioneered by Dr. R.N.S. Kulasinghe in early $80 \mathrm{~s}^{\prime}$ as a low cost and rapid construction technique. However, the mould used has not been able to harness the full potential of this construction technique. Semi mechanized mould developed in this study has effectively eliminated all the drawbacks of original version and allowed rapid construction of full wall height. In this study both economical aspect and strength of these new continuous masonry units have been evaluated and compared against the conventional brick masonry and results of the original slip form wall panel Results show that continuous masonry has significantly higher strength compared to conventional brick masonry. Detail cost analysis indicates that these continuous masonry wall panels can be constructed with substantial cost savings when compared with conventional brick masonry.
\end{abstract}

Keywords: Continuous masonry, constructability, structural behaviour of masonry walls, work study.

\section{Introduction}

Masonry wall panel construction is a vital component in any building construction. Wall panels in a building fulfil several functions. Acting as a load bearing elements is one of its primary functions. Fire protection, thermal and sound insulations, weather protection and partition are some of the other functions of wall panels. Different masonry materials have been used for the construction of wall panel in Sri Lanka. Clay bricks and cement sand blocks are the most usual typc. Low strength, high skill labour intensiveness, long duration of construction are some of the notable disadvantages of conventional brick masonry.

The strength of the conventional brick masonry is often affected by the poor quality of bricks produced. Local bricks have low strength and high variability making them unreliable for load bearing. This has led the engineers not to attribute any strength to masonry wall panels and use masonry only as infill in the reinforced concrete frame structures. However, attempts have been made to introduce new bricks, like cement stabilized block with improved strength characteristics, and new techniques of construction of brick walls to revitalize the role of brick wall as load bearing elements. Slip form construction pioneered by Dr A.N.S. Kulasignhe in the early $80^{\prime} \mathrm{s}$ is one such alternative technique for wall panel construction. This technique involved compaction of mortar between two shutters layer by layer until the full height of the wall is achieved[1][2][3]. Shutters are guided while raising and lowering along two concrete columns. There are many advantages of this method over conventional masonry construction. Low cost of the construction, high speed, minimum skill labour requirement, minimum wastage of materials and high dimensional accuracy are some of the notable advantages of this method over the conventional brick masonry[1][2].

At least 4 days are required to complete full wall height of conventional brick masonry with plaster applied. In conventional brick masonry, it is not possible to lay bricks or apply plaster for the full wall height in a continuous operation as they are not stable for such construction. Usually construction is withheld after $1.5 \mathrm{~m}$ height until it gains adequate strength. The slip form construction has the potential to eliminate the limitation of conventional brick masonry

J.M.N.U.J Manike is a graduate engineer of university of Ruhuma

Eng. (Dr.) H.P. Sooriyaarachchi, C. Eng, MIE (Sri I.anka), B.Sc. Eng. (Moratuma), M. Eilg. (Tokyo), PlnD. (Shoffield), Senior Ledurer in Cisil and Environmental Engineering, Faculty of Engineering, University of Ruhtuna, Hapugala, Galle. 
construction and complete the full wall height in a continuous operation. However, the mould originally used has its limitation in achieving the full potential of this construction technique. Figure 1 shows wall panel construction using the mould developed by Dr. R.N.S Kulashinghe whist Figure 2 shows the mould originally used in the construction. The main drawback of the mould used has been its inability to be tightened against the concrete edge columns during compaction and released during hoisting. Cracking of the freshly placed mortar is one of the main problems hindering the speedy progress of the construction [1]. This is caused when the shutters are raised without proper releasing. Raising shutters tend to lift the immediately compacted layer of masonry causing tensile stresses on the freshly placed mortar layer. In the original mould arrangement, a spreader beam is used while lifting the shutters. Hydraulic jacks lifting the shutter are placed on this spreader beam and reactions press the freshly placed mortar layer against the lift. This arrangement worked with some success but could not eliminate occasional cracking. Original wall panel construction also relied on the prestress precast edge columns to guide the shutter as the shutters could not tolerate the construction tolerances of the in situ cast column or any misalignment of the columns. This has further alienated the method from the common construction practice and it is rarely used today.

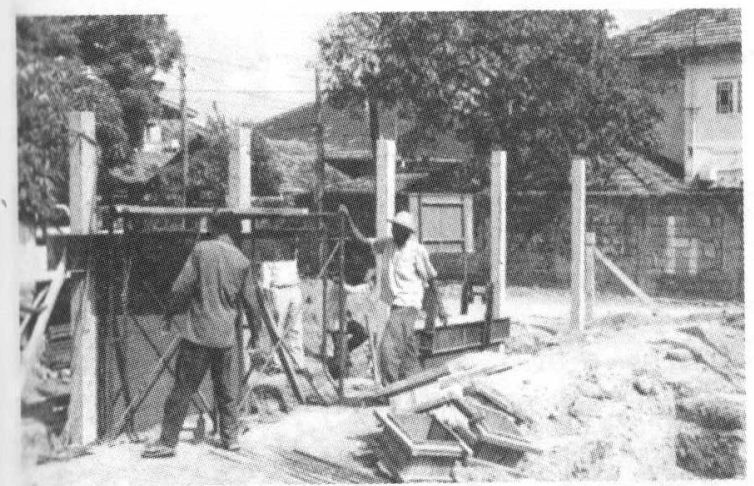

Figure 1: Construction of wall panels using Slip-form

Efficient construction of continuous masonry wall panels largely depends on the ability of the mould to continue construction without interruptions. The method also relies heavily on the suitable mortar mixes and the degree of compaction. In the original mixes, quarry dust cement mortar mixed with coconut coir was used. Water cement ratios of mixes were usually around 0.65 [1]. Higher water cement ratios can make the mortar stick to shutter while excessively dry mixers tends to disintegrate and become difficult to construct at the applied compaction effort. There is significant interdependency between the water/cement ratio and the degree of compaction for the constructability of a mix.

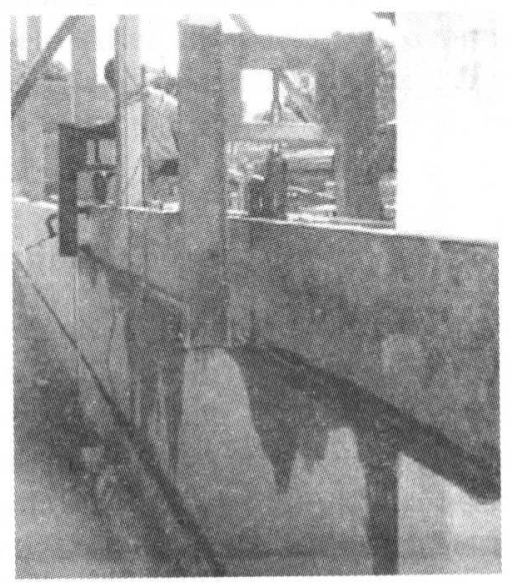

Figure 2: Mould used in the construction of slip form masonry.

\section{Methodology}

\subsection{Development of the mould}

This study is carried out with the main intension of improving a mould to yield the full potential of continuous masonry construction and find out the load bearing of such wall panels. Developed mould has effectively overcome the cracking of the wall during raising the shutters followed by compaction. Releasing and tightening mechanism that allows the shutters to move from the phase of construction during hoisting or tighten against the guiding concrete columns during compaction is the main feature of the newly developed mould. Figure 3 is a schematic representation of the developed mould with all the parts named. Fig 4 shows the releasing and tightening mechanism of the shutters. Ability to tight and release the shutters against the concrete edge column are achieved by attaching the shutters to the circular galvanised iron tube guides through a bridge jack. Bridge jack allows the shutters to move with respect to the galvanised iron tube guides and allow the shutters to be tightened against the column during compaction and release during hoisting. Galvanised iron tube guides are attached to the top and bottom of the concrete edge column and remain stationary during the construction. In the current mould, shutters are provided with chain blocks which are hung from the cross beam to allow them to be lifted and lowered with ease. Tightening and releasing mechanism 


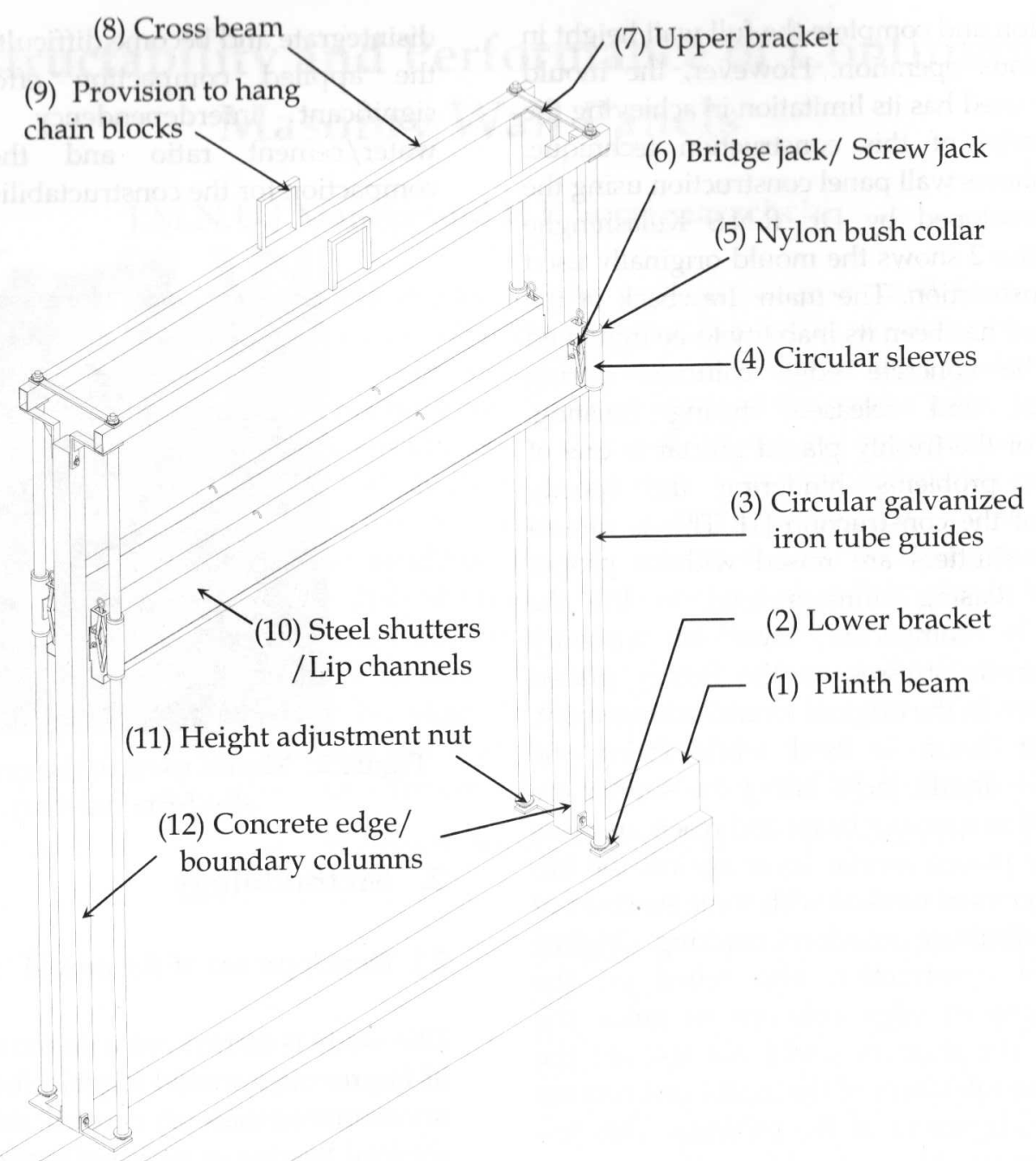

Figure 3: Schematic view of the developed mould with all the parts named

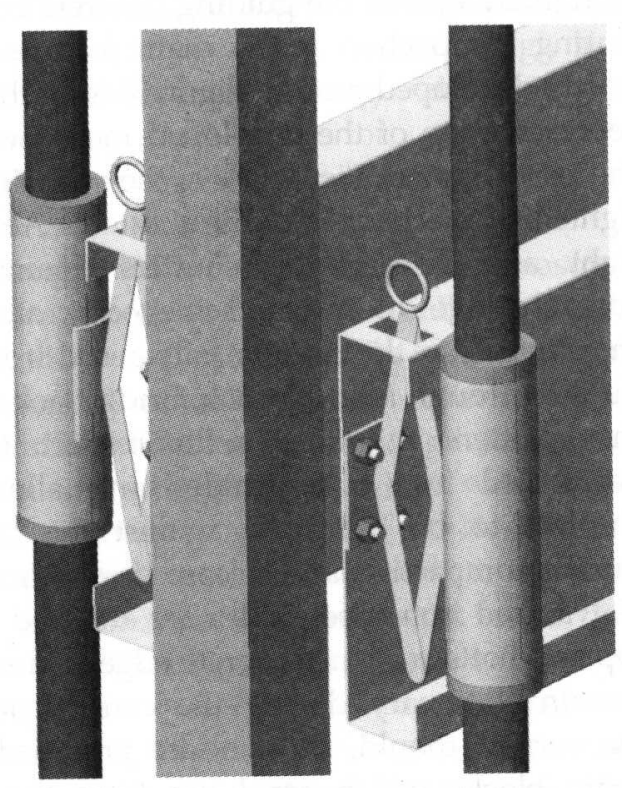

Schematic view of the mould

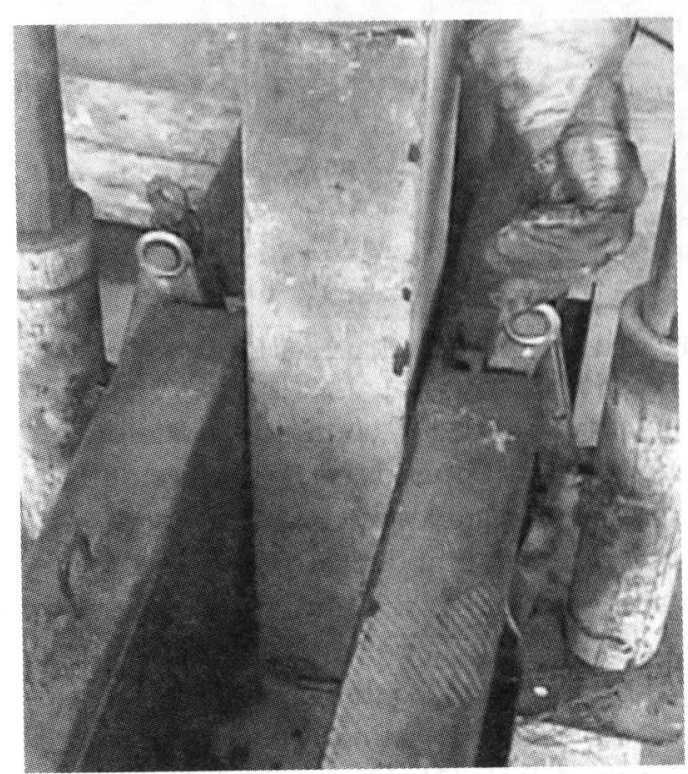

Photograph of the horizontal mechanism

Figure 4: Schematic view of the tightening and releasing mechanism of the shutters 
along with the effective guiding mechanism provided by the galvanised tube guides allow speedy masonry panel construction and to realize the full potential of the continuous masonry construction.

\subsection{Construction of wall panel}

Compaction of mortar to the required degree is a very important aspect of continuos masonry construction. Strength of finished wall and the constructability largely depends on the degree of compaction. Although plate compactor is ideal for this kind of compaction, due to unavailability demolition hammer is used in this study. Demolition hammer can be easily converted to deliver compaction effort by attaching a plate to the hammer bit and convert the hammer movement into a compaction effort. With all of these arrangements as explained above, it was possible to construct continuous masonry wall panel free of cracking and complete the construction of a full wall height in $6 \frac{1}{2} 2$ hours. Figure 5 shows the different processes involved in the construction of continuos masonry wall panel using the developed mould. First, the shutters were
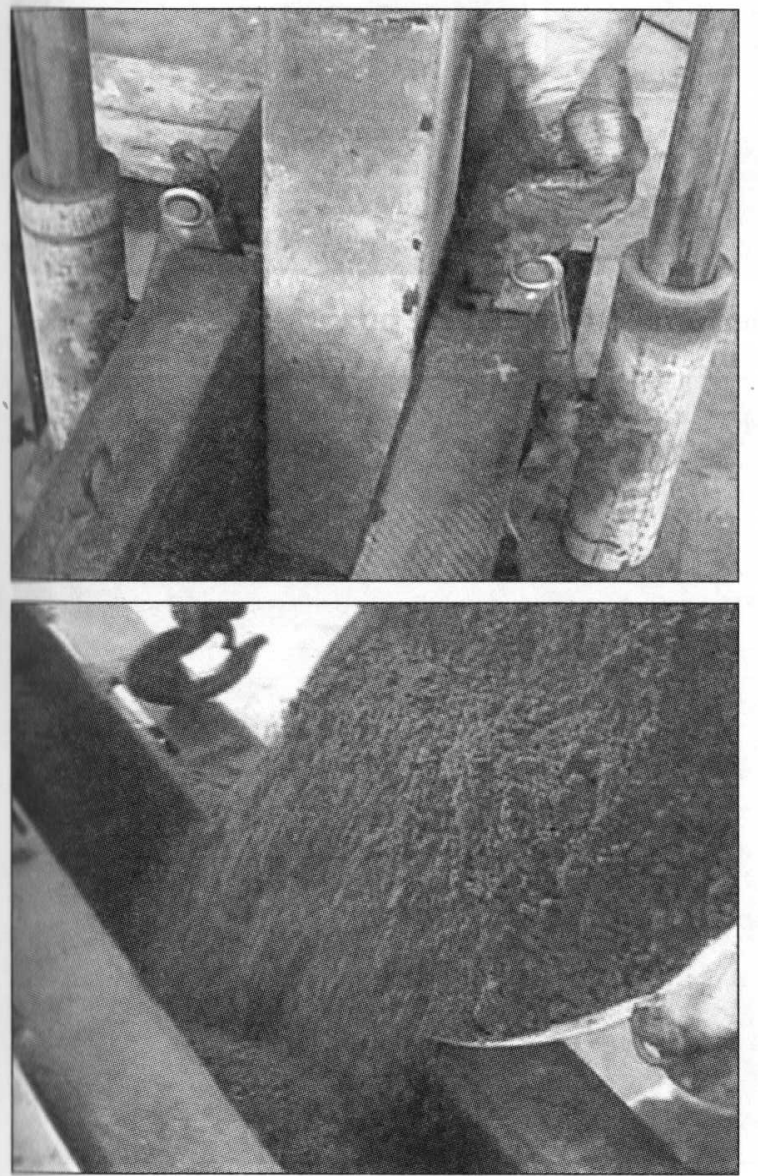

tightened against the concrete edges column. Then the mortar is placed between the two shutters and levelled. Next step is compaction. In all of the experimental investigation compaction is maintained to reduce 8 inches freshly placed mortar to 4 inches of finished wall panels. After compaction is over, shutters are released and raised to the next layer. This process is repeated until the full wall height is achieved.

\subsection{Selection of mixers}

Development of the mould to overcome the draw backs of the original system is the first step towards realising the full potential of the continuous masonry construction. Determining suitable mortar mixes that can be used in the construction of the full wall height is the next step. Both mixers with sand and quarry dust as aggregate were evaluated in this study. Different aggregate to cement ratios starting from low to high ratios were considered. Dry mixers with low water cement ratios are found most appropriate for this kind of construction. Usually water cement ratio between 0.4 and 0.5
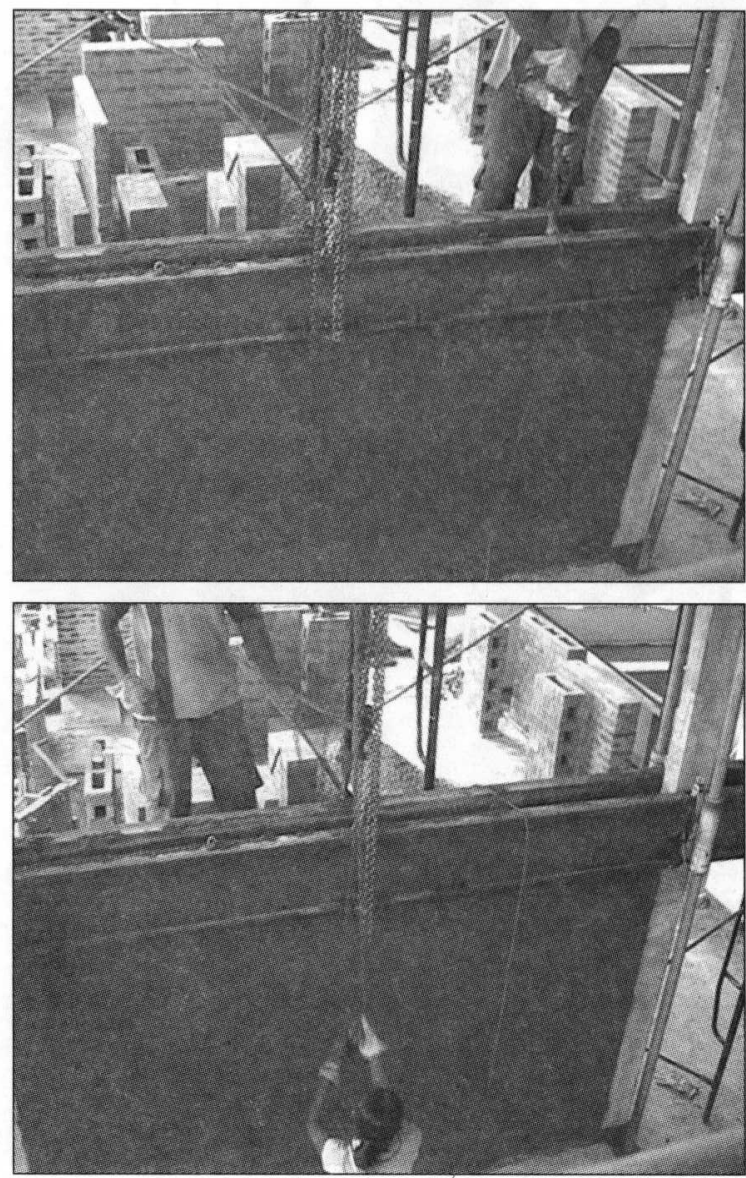

Figure 5: Sequence of steps involved in the continuos masonry construction (1) Tightening shutters (2) Placing mortar (3) Compaction (4) Releasing and raising the shutters to the next level 
were used. Suitability of a mortar mix was initially established by constructing a $500 \mathrm{~mm}$ strip of full wall height (Constructability test). Fig. 6 show work-in-progress of such strip of wall panel and successfully completed test.

Cement to aggregate ratio of 1:4 is considered as the first trail mix for both aggregates. After successful constructability test results, testing was extended for cement to aggregate ratio 1:6 and 1:8. It was found that it is difficult to construct cement to sand $1: 8$. With quarry dust as fine aggregate even 1:8 was easily achievable. However, further increase of cement to quarry dust ratio was found to be unrealistic as the surface texture became coarser at increasing cement to quarry dust ratio. Mixer that satisfies the constructability test at maximum aggregate to binder ratio (1:6 for sand 1:8 for quarry dust) with relevant water binder ratio was then used in a full wall panel construction $(3.5 \times 3.5 \mathrm{~m}$ wall panel) to confirm the stability of the mixers in full wall construction. Figure 6(a) and 6(b) show the full wall panel constructed with 1:6 cement to sand mix and 1:8 cement to quarry dust mix. As it was possible to extend the mixers that pass the constructability test to a full wall panel
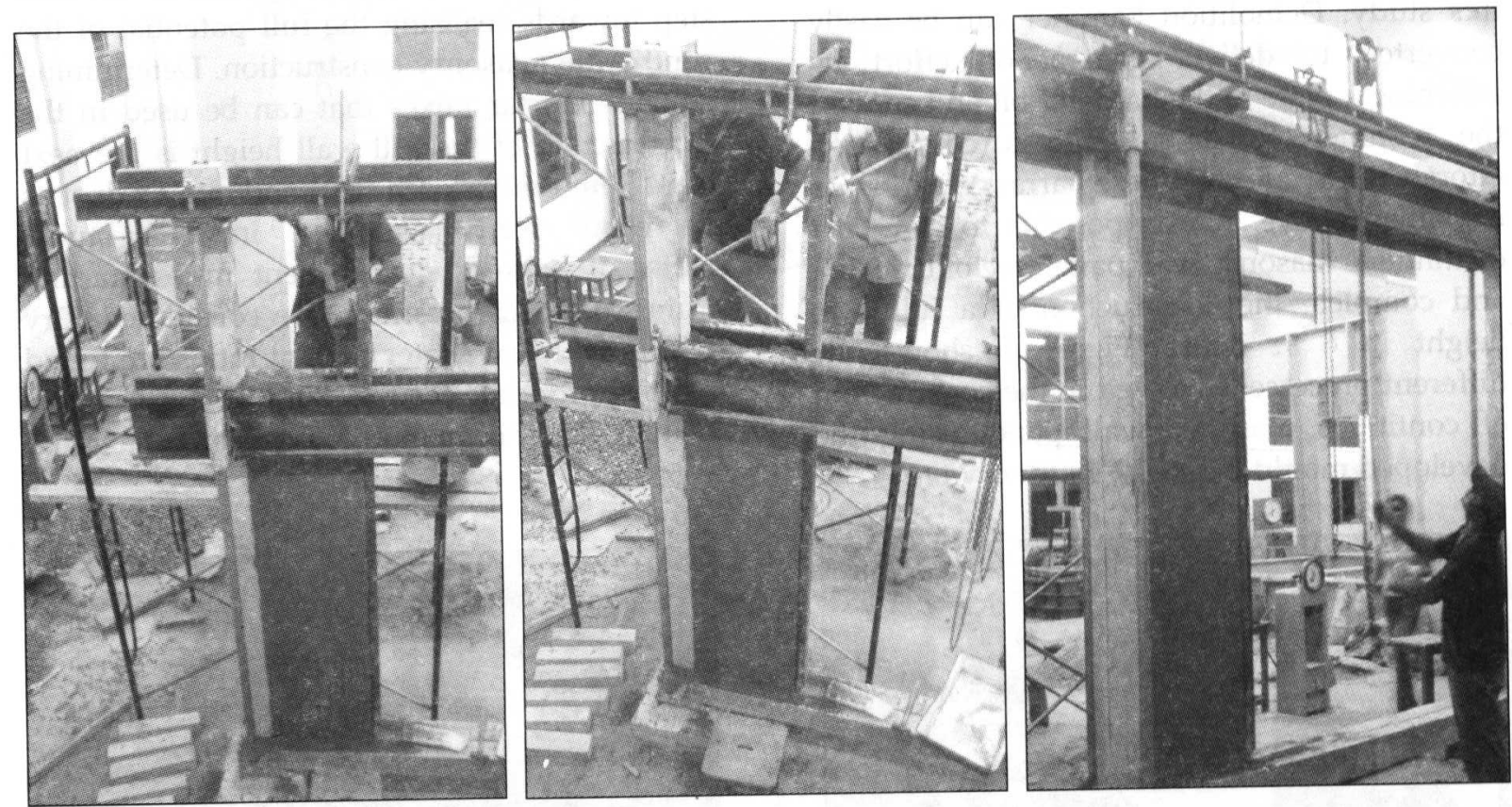

Figure 6: Constructability test performed for a mortar mix

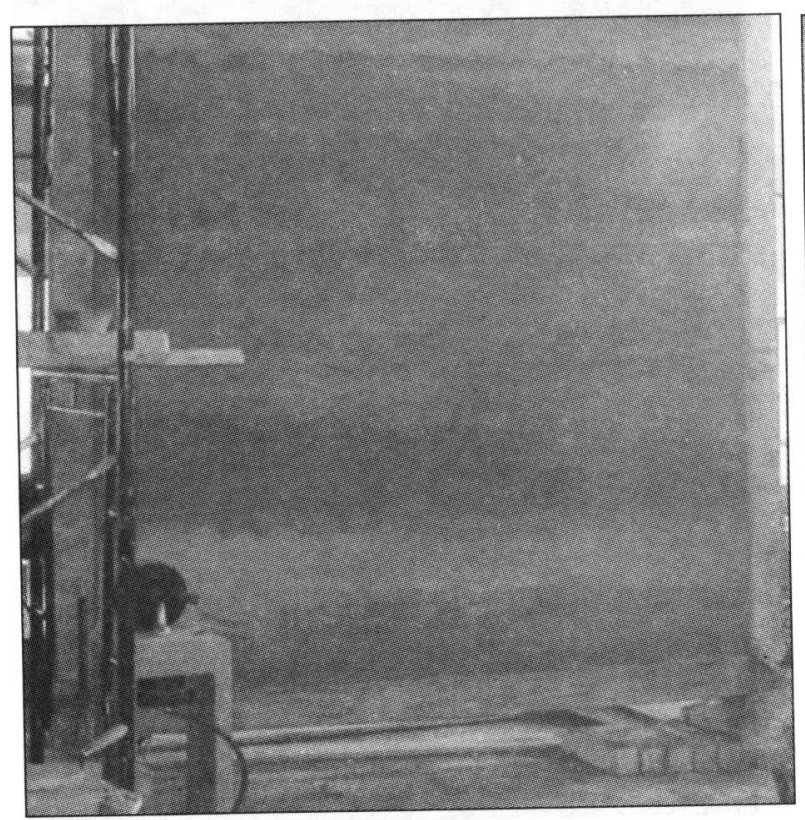

(a) 1:6 sand cement mortar

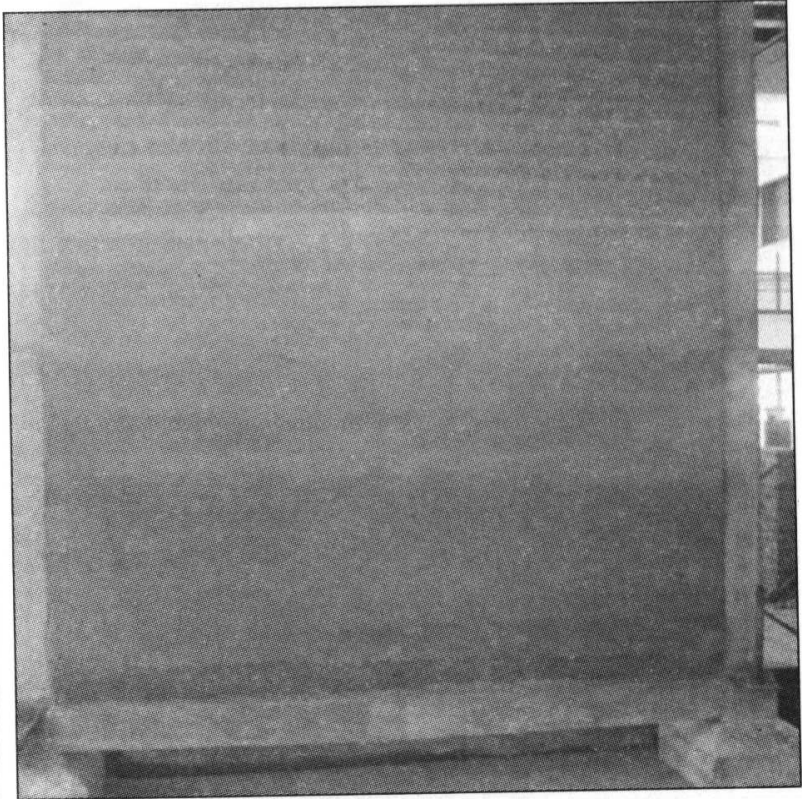

(b) 1:8 Quarry dust cement con

ade

and

con

An

text

qu.

cen

sur

agt

the

hig

ma

cor

Stri

$\mathrm{mi}$

as

wa

3.

Le
w
hi
po
$q$ i
m
w
le
C
e

Figure 7: Full wall panel construction with maximum aggregate to cement ratio 
construction, constructability test deemed adequate for the selection of mix proportions and water/cement ratio of mixers in the continuous masonry construction.

Angular shape and course aggregate surface texture of quarry dust has probably made the quarry dust mixers stable at higher aggregate to cement ratios. Spherical shape and smooth surfaces of sand has made it unstable at higher aggregate to cement ratios. Quarry dust, being the cheaper of the two aggregate type and higher aggregate to cement ratios possible makes it the cheaper of the two material for the construction of continuos masonry wall panels. Strength test was conducted only with the mixes with maximum aggregate to cement ratio as they are the most economical mixes for the wall panel construction.

\section{Testing of wall panels for compressive strength}

Load bearing capacity of continuous masonry wall panels are found using $0.6 \mathrm{~m}$ long $\times 0.45 \mathrm{~m}$ high test panel (see Figure 8). Continuous wall panels with 1:6 cement: sand ratio, 1:8 cement:: quarry dust ratio and conventional brick masonry of 9"width English bond (one brick width) and half brick were cast for testing. At least there specimens were cast form each mix. Conventional brick specimens were cast for comparison purposes and they were cast from were used at the top and bottom to avoid pressure variations on the wall during testing. Dial gauges were placed on the specimens to measure vertical deformation of wall with the increasing load.

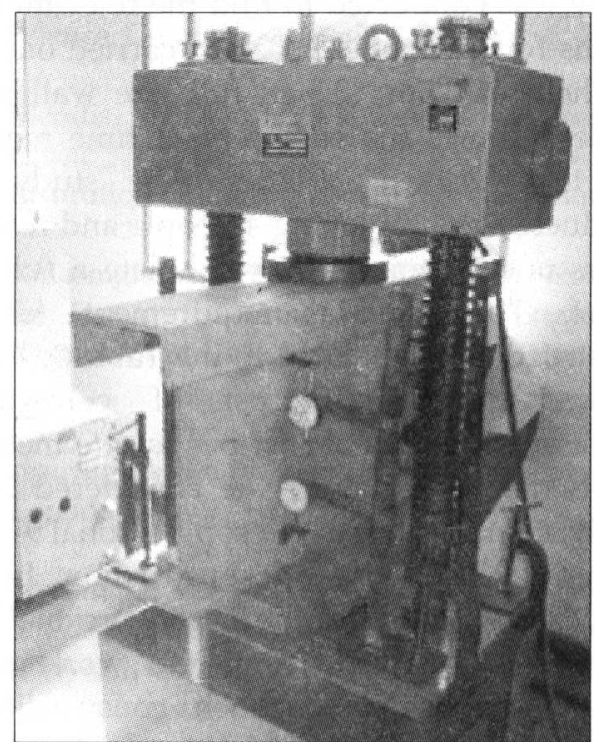

Figure 8: Testing for compression

Table 1 shows the compressive strength of the continuous wall panels compared with the conventional masonry constructed with different mortar designations. In terms of ultimate stress, continuous masonry is found to have strength in excess of 7-8 times of conventional masonry. This is 4-5 times of the 9 inch burnt clay bricks in terms of load bearing per unit length of masonry. Therefore it is clear

Table 1. Compressive stregnth of different masonry wall pannels

\begin{tabular}{|c|c|c|c|c|}
\hline Motor & Panel size & Panel Type & $\begin{array}{r}\text { Load } \\
(\mathrm{kN})\end{array}$ & Strength(N/mm²) \\
\hline $1: 7$ & $4^{\prime \prime}$ & brick & 67.7 & 1.23 \\
\hline $1: 7$ & $9^{\prime \prime}$ & brick & 153.3 & 1.114 \\
\hline $1: 5$ & $4^{\prime \prime}$ & brick & 130.7 & 2.375 \\
\hline $1: 5$ & $9^{\prime \prime}$ & brick & 213.7 & 1.665 \\
\hline $\mathbf{1 : 6}$ & $\mathbf{4}^{\prime \prime}$ & $\begin{array}{c}\text { Continuous } \\
\text { (Cement: sand mix) }\end{array}$ & $\mathbf{8 9 0 . 0}$ & $\mathbf{1 1 . 8 1}$ \\
\hline $\mathbf{1 : 8}$ & $\mathbf{4}^{\prime \prime}$ & $\begin{array}{c}\text { Continuous } \\
\text { (Cement: Quarry dust mix) }\end{array}$ & 748.0 & $\mathbf{1 0 . 3 9}$ \\
\hline $\mathbf{1 : 1 0}$ & $\mathbf{4}^{\prime \prime}$ & $\begin{array}{c}\text { Slip form original (Cement } \\
\text { quarry dust mix wit coir) [1] }\end{array}$ & & $\mathbf{2 . 1 3 ~ 3 . 1 4}$ \\
\hline
\end{tabular}

both Class I (1: 5 Cement to sand) and Class II (1:7 Cement to sand) mortar designations. Prepared wall panels were tested after 28 days from its preparation. Continuous curing was carried out in the first seven days. Fig. 7 show the arrangement used for testing masonry wall panels. In all of the specimens, timber planks that the continuous masonry wall panel is much more superior in structural performance to the brick masonry and can easily be used as load bearing masonry. It is also seen that there is a significant improvement in the strength of current continuos wall panel construction compared to the original slip form construction. 


\section{Cost analysis}

As continuous masonry is a novel technique, there were no existing work norms for this method of construction. Therefore, a work study was conducted to find the relevant work norms for the method. This is carried out with the help of $3.5 \mathrm{~m} \times 3.5 \mathrm{~m}$ full size wall panel. Table 2 shows the summery of time required for the various activities. The study was conducted by employing 4 people and it took 6 hours and 30 minutes to complete a full wall panel. The material requirement for the construction is tabulated in the Table 3 . Table 4 shows the overall cost of construction expressed in terms of cost per square meter for the two types of aggregate considered in the study, compared with the conventional 9" brick masonry. The cost of construction In this analysis, unit price for the 9" conversional brick masonry is arrived using the work norms already published for such construction in building schedule of rates (BSR). Price for material and labour have been worked out at the prevailing rates in the market at the time of research (February 2008).

The cost of construction of the continuos wall panel in the Table 4 does not include the cost absorption from the mould and modified demolishing hammer as it is still to early to make an good estimate on that for a square meter of wall. Initial investment on the mould was around Rs. $30,000 /=$ and the demolition hammer with customised drill bit to deliver compaction effort cost another Rs. 40,000/=. As these can be repeatedly used for significantly large number of times, the cost per square meter is expected to be very small. Electricity power is also not accounted for due to variable tariff. During the work study, hammer ( 800 Watts) is estimated to have worked $1 / 3$ of the total duration of the construction and consumed about $2 \mathrm{kWh}$ of electricity for the $3.5 \mathrm{~m} \times 3.5 \mathrm{~m}$ wall panel.

Table 2. Results of the time study on continuous masonry wall panel construction.

\begin{tabular}{ll}
\hline Activity & Time taken \\
\hline Mould assembly & $40 \mathrm{~min}$ \\
\hline Time for motor feeding and compaction per layer & $10 \mathrm{~min}$ \\
$(4$ inches of finish wall $)$ & $5 \mathrm{hr} 30 \mathrm{~min}$ \\
\hline Total construction time for $3 \times 3 \mathrm{~m}$ wall $(\approx 100$ square feet $)$ & $10 \mathrm{~min}$ \\
\hline Dismantling of the mould & 6 hours and 30 minutes \\
\hline Total time &
\end{tabular}

Table 3. Material and Labour use in the construction of $3.5 \times 3.5 \mathrm{~m}$ wall panel.

\begin{tabular}{|l|c|c|}
\hline \multicolumn{1}{|c|}{ Material and Labour } & $\begin{array}{c}\text { Continuous masonry } \\
\text { Cement: sand(1:6) }\end{array}$ & $\begin{array}{c}\text { Continuous masonry, } \\
\text { Cement: Quarry Dust(1:8) }\end{array}$ \\
\hline Cement (bag contain $50 \mathrm{~kg}$ ) & 6 bags & 3.5 bags \\
\hline Sand $\mathrm{m}^{3}$ & $0.52 \mathrm{cube}$ & - \\
\hline Quarry Dust $\mathrm{m}^{3}$ & - & $0.42 \mathrm{cube}$ \\
\hline Labour & 4 persons for $61 / 2$ hours & 4 persons for $61 / 2$ hours \\
\hline Water: cement & $0.5^{*}$ & $0.6^{*}$ \\
\hline
\end{tabular}

Table 4. Cost construction of different wall panel types.

\begin{tabular}{|c|c|c|}
\hline $\begin{array}{c}\text { Continuous masonry with } \\
\text { Cement: Quarry Dust (1:8) }\end{array}$ & $\begin{array}{c}\text { Continuous masonry with } \\
\text { Cement: Sand }(1: 6)\end{array}$ & $\begin{array}{c}\text { Conventional One Brick thick } \\
\text { wall with } 1: 5 \text { Cement : Sand }\end{array}$ \\
\hline Rs. 670.00 per $\mathrm{m}^{2}$ & Rs. 960.00 per $\mathrm{m}^{2}$ & Rs. 2145.33 per $\mathrm{m}^{2}$ \\
\hline
\end{tabular}




\section{Discussion and Conclusions}

Industry is always searching for economical, time saving construction methodologies which suits to replace the conventional methods. Continuous masonry construction is in the right direction to achieve those objectives. From the cost analysis it is clear that the continuous masonry can reduce the cost of construction. As larger cement to aggregate ratios can be used with quarry dust as fine aggregate saving can be even higher when quarry dust is used as the aggregate. Cost of construction quarry dust masonry is found to one third of that of conventional masonry. The cost comparison in the current cost analysis doesn't account for the initial expenses for mould and the compactor or the electricity consumed for the compaction. However, it is of the view that those elements of cost would not alter the above cost ratio in any significant way.

In terms of compressive behaviour it is found that continuous masonry perform far superior to conventional brick masonry and therefore is a better alternative for load bearing wall construction. Continuous masonry is homogeneous in its composition as against the brick masonry. Due to the existence of bricks, layers of mortar and discontinuities in the form of bond between brick and masonry conventional masonry are non homogeneous materials. In the structural performance point of view, bond between the bricks and mortar is considered to be the weakest link especially when the brick panels are subjected to bending. Continuous masonry on the other hand has eliminated such weaknesses and therefore is expected to perform even better under flexural loading.

Semi-mechanized mould system which is developed to construct continuous masonry wall panels has been found very effective and has now been developed as a completely independent building system. Only disadvantage of this method is its lack of flexibility. If operated on one shutter length it can only produce wall panel with multiples of the shutter length. However, with proper planning, acceptable living spaces can be made with even one shutter length. By increasing the number of shutter lengths which can be easily arranged to mount to the same driving mechanism more flexibility can be introduced into the construction.

\section{References}

1. Dissanayake T.A., Dissanayake U.I., Ranaweera M.P., (2001), "Material Properties of slip-formed load bearing wall panels for low-cost medium-rise buildings", Fifty Seventh Annual Session of Sri Lanka Association for the Advancement of Science. Colombo.

2. Mendis, D.L.O., (2001), "Innovation and Selfrelianc", Kulasinghe Felicitation Volume, Institution of Engineers of Sri Lanka, Colombo.

3. Kulasinghe A.N.S., (2000) "Kulasinghe technology for low cost housing", National Engineering Research and Development Centre, Colombo.

4. BS 5628 : Part 1: 1978, "Code of practice for structural masonry - Un-reinforced masonry", BSI, London.

5. Jayasinghe M.T.R, (1997) "Load bearing brickwork construction for Sri Lanka", STRAD Consultants (Pvt) Ltd, Colombo

6. Kulatilleke M.P.M., (2002) "A study on the characteristics of cement blocks manufactured in Sri Lanka", MSc Thesis, University of Peradeniya,

7. Appuhamy J.M.R.S., Chandrasekara H.K.C.P., Ruhunage J.C., Dissanayake T.A., Dissanayake U.I.,(2003) "Strength variation of slip formed load bearing wall panels made of cement and crusher dust with partial replacement of crusher dust by river sand", submitted to Fifty Ninth Annual Session of Sri Lanka Association for the Advancement of Science. December/2003

8. Henry A.W, (1990) "Structural Masonry", MacMillon Press, London, 284 pp.

9. Jayasinghe, C., (2008) "Comparative performance of Burnt Clay Bricks and Compressed Stabilized Earth Bricks and Blocks", Journal of the institution of Engineers, Sri Lanka, Vol: xxxx, No: 02, April 2007, 33-40 pp. 